\title{
Vitamin D Is Associated with Severity and Mortality of Non-alcoholic Fatty Liver Disease: A US Population-based Study
}

\author{
Hyun-Seok Kim ${ }^{1}$, Laura Rotundo ${ }^{1}$, Neil Kothari ${ }^{1}$, Sung-Hoon Kim*3 \\ and Nikolaos Pyrsopoulos*2 \\ ${ }^{1}$ Department of Medicine, Division of Gastroenterology and Hepatology, Rutgers New Jersey Medical School, Newark, NJ, USA; \\ ${ }^{2}$ Division of Gastroenterology and Hepatology, Rutgers New Jersey Medical School, Newark, NJ, USA; \\ ${ }^{3}$ College of Korean Medicine, Kyung-hee University, Seoul, South Korea
}

\begin{abstract}
Background and Aims: There has been increasing evidence that vitamin D deficiency may increase the risk of metabolic syndrome. Since metabolic syndrome is a major risk factor for non-alcoholic fatty liver disease (NAFLD), we aimed to investigate the association between vitamin $D$ and the severity and mortality of NAFLD. Methods: Data was obtained from the United States Third National Health and Nutrition Examination Survey conducted in 1988-1994, with followup mortality data through 2011. NAFLD was defined by ultrasonographic detection of hepatic steatosis in the absence of other liver diseases and categorized as normal, mild, moderate or severe. The severity of hepatic fibrosis was determined by NAFLD fibrosis score (NFS). ANOVA (F-test) was used to evaluate the association between vitamin $D$ level and degree of NAFLD, and Cox proportional hazards regression analysis was used for survival analyses. Results: Vitamin D levels for normal, mild, moderate and severe steatosis were $25.1 \pm 0.29 \mathrm{ng} / \mathrm{mL}, 24.7 \pm 0.42 \mathrm{ng} / \mathrm{mL}, 23.7 \pm 0.37 \mathrm{ng} / \mathrm{mL}$ and $23.6 \pm 0.60 \mathrm{ng} / \mathrm{mL}$, respectively (trend $p<0.001$ ). Likewise, vitamin $D$ levels for low, intermediate and high NFS categories were $24.7 \pm 0.38 \mathrm{ng} / \mathrm{mL}, 23.4 \pm 0.42 \mathrm{ng} / \mathrm{mL}$ and $21.5 \pm 0.57 \mathrm{ng} / \mathrm{mL}$, respectively (trend $p<0.001$ ). After median-follow up over 19 years, vitamin D deficiency was significantly associated with diabetes- and Alzheimer's diseaserelated mortality (hazard ratio (HR): 3.64, 95\%CI: $1.51-8.82$ and HR: 4.80, 95\%CI: $1.53-15.1$, respectively), with a borderline significance in overall mortality (HR: $1.16,95 \% \mathrm{CI}$ : $0.99-1.36, p=0.06)$. Conclusion: Vitamin $\mathrm{D}$ level was inversely related to the degree of liver steatosis and fibrosis.
\end{abstract}

Keywords: Vitamin D; Non-alcoholic fatty liver disease; Mortality; Severity. Abbreviations: ALT, alanine aminotransferase; AST, aspartate aminotransferase; BMI, body mass index; CI, confidence interval; HbA1c, glycated hemoglobin; HOMA-IR, homeostasis model assessment of insulin resistance; HR, hazard ratio; IGF-1, insulin-like growth factor-1; NAFLD, non-alcoholic fatty liver disease; NASH, non-alcoholic steatohepatitis; NFS, NAFLD fibrosis score; NHANES, National Health and Nutrition Examination Survey; REF, reference; SE, standard error; UCOD, underlying cause of death.

Received: 28 March 2017; Revised: 17 May 2017; Accepted: 23 May 2017

*Correspondence to: Nikolaos Pyrsopoulos, Division of Gastroenterology and Hepatology, Rutgers-New Jersey Medical School, 185 South Orange Avenue, MSB H538, Newark, NJ 07101-1709, USA. Tel, +1-973-972-5252, Fax: +1-973972-3144, E-mail: pyrsopni@njms.rutgers.edu; Sung-hoon Kim, College of Korean Medicine, Kyung-hee University, Seoul, South Korea. Tel: +82-2-9619233, Fax: +82-2-964-1054, E-mail: sungkim7@khu.ac.kr
Moreover, vitamin D deficiency was associated with diabetesand Alzheimer's disease-related mortality in NAFLD patients. Citation of this article: Kim HS, Rotundo L, Kothari N, Kim $\mathrm{SH}$, Pyrsopoulos N. Vitamin D is associated with severity and mortality of non-alcoholic fatty liver disease: a US populationbased study. J Clin Transl Hepatol 2017;5(3):185-192. doi: 10.14218/JCTH.2017.00025.

\section{Introduction}

Vitamin D and its possible role in the development of chronic diseases has been the focus of recent studies. Long recognized as important for maintaining bone health, it has also been found to be associated with cancer, cardiovascular disease, type 2 diabetes mellitus, insulin resistance, and metabolic syndrome. ${ }^{1-4}$ Along with this, there is growing attention to non-alcoholic fatty liver disease (NAFLD) as a hepatic manifestation of metabolic syndrome. ${ }^{5}$ NAFLD represents a wide spectrum of clinicopathologic conditions, from simple hepatic steatosis to nonalcoholic steatohepatitis (NASH) and cirrhosis; currently, it is the most common cause of chronic liver disease. ${ }^{6}$

Although a few studies have reported the possible role of vitamin D deficiency in the degree of NAFLD, these studies evaluated a small patient population, and the findings are inconsistent regarding whether or not the level of vitamin $D$ affects the severity of NAFLD. ${ }^{7-9}$ Moreover, to our knowledge, there is no published United States population-based study that represents the entire national household. It has been reported that NAFLD is a major cause of death associated with obesity, diabetes and cardiovascular disease. ${ }^{10-12}$ Since vitamin $D$ level has been associated with these metabolic disorders, it would be important to investigate whether vitamin D level can be a prognostic factor in NAFLD. Currently, the role of vitamin $D$ in the mortality of NAFLD remains to be elucidated.

Thus, the purpose of this study was to (i) investigate the association between vitamin D level and severity of NAFLD and (ii) explore whether vitamin D level can predict mortality in NAFLD patients, using nationally representative crosssectional data with subsequent follow-up mortality data. 
Methods

\section{Study population}

The Third National Health and Nutrition Examination Survey (NHANES III) is a cross-sectional, population-based sample survey of the civilian non-institutionalized population of the United States conducted from 1988 through 1994. This survey was conducted by a complex, stratified and multistage probability sampling design and obtained information using standardized household interviews, physical examinations and testing of biologic samples. Detailed information about design and sampling of the survey is available. ${ }^{13}$

Participants were included in this study if they met the following selection criteria (Fig. 1): age of 20-74 years-old, available clinical and laboratory variables, liver ultrasound data, and mortality follow-up data. Those with heavy alcohol consumption ( $\geq 21$ drinks/week for men and $\geq 14$ drinks/week for women), viral hepatitis (positive serum hepatitis $B$ surface antigen or serum hepatitis $C$ antibody), iron overload (transferrin saturation of $\geq 50 \%$ ) or pregnancy were excluded $(n=1,720)$. After the selection process, 10,960 participants were included. The original survey was approved by the Centers for Disease Control and Prevention's Institutional Review Board, and all participants provided written informed consent to participate.

\section{Clinical and laboratory data}

A wide array of demographic, lifestyle and dietary information as well as anthropometric assessment and comprehensive laboratory data are available in the data set. ${ }^{14-16}$ Hypertension was defined as systolic blood pressure of $\geq 140 \mathrm{mmHg}$ or diastolic blood pressure of $\geq 90 \mathrm{mmHg}$ and/or previous use of antihypertensive medication or self-reported hypertension diagnosis. Diabetes mellitus was diagnosed in subjects with history of diabetes diagnosis and/or treatment with a hypoglycemic agent or insulin. Insulin resistance was defined by $>3.5$ score in the homeostasis model assessment of insulin

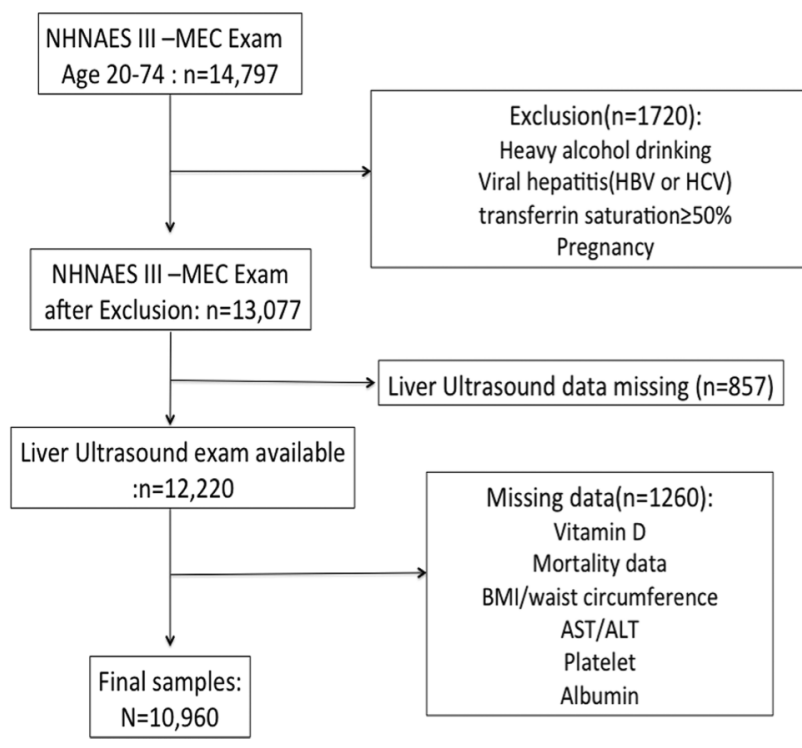

Fig. 1. Consort diagram of patient selection. Adopted from Kim et al. ${ }^{23}$ resistance (HOMA-IR; or serum glucose $x$ serum insulin/ 22.5). ${ }^{17}$ Smoking status was categorized as current, former or never smoker. Education level was treated as binary (below college vs. college or higher), and poverty index was classified with cut-offs of 1.3 and 1.85 , according to the poverty guidelines. ${ }^{18}$ Metabolic syndrome was defined according to the National Cholesterol Education Program Adult Treatment Panel (commonly known as the NCEP ATP III) definition. ${ }^{19}$ History of cardiovascular disease was defined as self-reported history of congestive heart failure, stroke or myocardial infarction. Vitamin D level was measured using Diasorin 25-OH-D assay and deficiency was defined as a level below $20 \mathrm{ng} / \mathrm{dL}^{20}$ Serum leptin concentrations were measured by radioimmunoassay at Linco Research, Inc (St Charles, MO, United States) ${ }^{21}$ and insulin-like growth factor-1 (IGF-1) was measured by IGF-1 enzyme-linked immunosorbent assay (DSL 10-5600; Diagnostic Systems Laboratories, Webster, TX, United States)..$^{22}$

\section{NAFLD}

The original NHANES III examination included ultrasonography of the liver and gallbladder at a mobile examination center as a part of the assessment for digestive diseases in adults aged 20 to 74 years-old. Subsequently, the archived gallbladder ultrasound video images were reviewed to assess fatty liver. $^{23}$ Three ultrasound reviewers were trained by a board certified radiologist, who was specialized in hepatic imaging. Evaluation of the fatty liver was performed using the following five criteria: 1) parenchymal brightness, 2) liver-to-kidney contrast, 3) deep beam attenuation, 4) bright vessel walls, and 5) gallbladder wall definition. The overall assessment, by an algorithm based on these five criteria, reported normal versus mild, moderate or severe hepatic steatosis. We defined NAFLD as subjects with any degree (mild to severe) of steatosis. In individuals with NAFLD, NAFLD fibrosis score (NFS) was used to assess severity of liver fibrosis. ${ }^{24}$

NFS was calculated as: $-1.675+0.037 X$ age (years) + $0.094 X$ body mass index $\left(B M I ; \mathrm{kg} / \mathrm{m}^{2}\right)+1.13 \times$ impaired fasting glycemia or diabetes (yes $=1$, no $=0$ ) + 0.99X aspartate aminotransferase (AST)/alanine aminotransferase (ALT) ratio $-0.013 \times$ platelet $\left(X 10^{9} / \mathrm{L}\right)-0.66 \times$ albumin $(\mathrm{g} / \mathrm{dL})$

Two cut-off points were selected to categorize subjects with NAFLD into three groups, including those with high probability (NFS > 0.676), intermediate probability (NFS 0.676 to -1.455 ) and low probability for advanced fibrosis (NFS $\leq-1.455)$.

\section{Mortality}

All participants of NHANES III over 17 years of age were passively followed for mortality through December 31, 2011, by linking NHANES III participants with National Death Index records through a probabilistic match, a well-established matching method. The NHANES III-Linked Mortality File uses the Underlying Cause of Death 113 (UCOD_113) code to classify all deaths according to the International Classification of Diseases, 9th Revision (ICD-9) for deaths prior to 1998 and to ICD-10 for those between 1999 and $2011 .{ }^{25}$ Overall mortality and the following leading cause-specific mortalities were assessed: (1) cardiovascular-related (UCOD_113 54-64); (2) malignancy-related (UCOD_113 19-43); (3) cerebrovascular-related (UCOD_113 70); (4) lung-related (UCOD_113 82-86, 76-78); (5) kidney-related (UCOD_113 97-101); 
(6) diabetic-related (UCOD_113 046), and (7) Alzheimer's disease-related (UCOD_113 052). Liver-related mortality could not be investigated since it was classified as 'others' in the public version of mortality data.

\section{Statistical analysis}

All data was analyzed using the 'survey' package in R software version 3.2.2. ${ }^{26}$ We analyzed frequencies of categorical variables and means \pm standard errors (SEs) of continuous variables. Baseline characteristics across groups were compared using the chi-square test for categorical variables and the two sample $t$-test or ANOVA for continuous variables. The trending of degree of NAFLD was tested by treating steatosis status and NFS category as an ordinal variable. To calculate the hazard ratios (HRs), Cox proportional hazards regression analysis was used for survival analysis, including overall and disease-specific mortality.

In the analysis of association of vitamin $D$ and degree of NAFLD and fibrosis, both unadjusted and adjusted models were used. Factors included in the limited model were age, sex, race, census region and season, while other metabolic disorder-related factors (hypertension, diabetes, dyslipidemia, BMI, metabolic syndrome, HOMA-IR, leptin, IGF-1) were added to our full model. For survival analyses, HRs were calculated by adjusting for age, sex and race. $p$-values were two-sided, and a $p$-value of $<0.05$ was considered to indicate statistical significance. All analyses utilized sample weights that accounted for unequal selection probabilities and nonresponse. All variance calculations accounted for the design effects of the survey using Taylor series linearization. ${ }^{27}$

\section{Results}

\section{Demographics}

From 1988 to 1994 , there were 10,960 NHANES participants who met our selection criteria (Fig. 1). Among them, 4,991 individuals were classified as having vitamin $\mathrm{D}$ deficiency, corresponding to a weighted prevalence of $30.8 \%$ (95\% confidence interval (CI): 28.2-33.4) (Table 1). The vitamin D-deficient population tended to be older, more female predominant, of non-white ethnicities, current smokers, had blood drawn in winter, and lived in the South and West regions. People with vitamin D deficiency had higher BMI, waist circumference, waist-to-hip ratio and HOMA-IR score as well as higher levels of glycated hemoglobin (HbA1c), triglycerides, r-GT, platelets and leptin. They also had a higher incidence of hypertension, diabetes, insulin resistance and metabolic syndrome. Vitamin D deficiency was associated with low albumin and IGF-1.

\section{Vitamin D level by degree of NAFLD on liver ultrasound finding}

Table 2 and Fig. 2A show the relationship between vitamin D levels by the degree of fatty liver based on liver ultrasound findings (normal, mild, moderate or severe). Among the 10,960 people in our cohort, 4,015 (34.3\%) were identified with NAFLD. There were 1,491 people with mild, 1,707 with moderate and 817 with severe steatosis. In the total population, vitamin $\mathrm{D}$ level had a significant inverse relationship with the degree of fatty liver disease (for normal, mild, moderate and severe steatosis, levels were $25.1 \pm 0.29 \mathrm{ng} / \mathrm{mL}$,
$24.7 \pm 0.42 \mathrm{ng} / \mathrm{mL}, 23.7 \pm 0.37 \mathrm{ng} / \mathrm{mL}, 23.6 \pm 0.60 \mathrm{ng} / \mathrm{mL}$, respectively (trend $p<0.001)$ ). The relationship remained significant after adjusting for known demographic factors including age, sex, race, census region and season of the study (limited model). However, the significance disappeared after adjusting for metabolic risk factors such as hypertension, diabetes, BMI, metabolic syndrome, HOMAIR, leptin and IGF-1 levels (full model), suggesting that vitamin $D$ may be placed on the same causal pathway with these factors and highly correlated. Table S1 showed that vitamin $\mathrm{D}$ level significantly correlated with metabolic risk factors, with leptin having the highest correlation coefficient $(r=-0.24)$. Similar relationship trends were observed among both sexes and all racial groups, with the exception of the non-Hispanic black group.

\section{Vitamin D level by degree of NFS}

Table 3 and Fig. 2B show the relationship between the vitamin D level and NFS category. There were 2,354 people with low NFS ( $\leq-1.455), 1,379$ people with intermediate NFS, and 282 people with high NFS $(>0.676)$. In the total population, vitamin D level was inversely related to the NFS category $(24.7$ $\pm 0.38 \mathrm{ng} / \mathrm{mL}, 23.4 \pm 0.42 \mathrm{ng} / \mathrm{mL}$, and $21.5 \pm 0.57 \mathrm{ng} / \mathrm{mL}$ for low, intermediate and high NFS, respectively (trend $p<0.001)$ ). This statistical significance remained after known demographic variables were taken into account (limited model), while it disappeared after adjusting for other metabolic risk factors of NAFLD (full model). In the subgroup analyses, a similar trend was only observed in the female group (23.7 $\pm 0.49 \mathrm{ng} / \mathrm{mL}, 21.5 \pm 0.54 \mathrm{ng} / \mathrm{mL}$ and $19.2 \pm 0.75 \mathrm{ng} / \mathrm{mL}$ for low, intermediate and high NFS, respectively (trend $p<0.001$ )) and non-Hispanic whites. An inverse association between vitamin D levels and NFS group existed in the Hispanic group, but the association was not robust enough to be significant after adjustment.

\section{Mortality by vitamin D status in NAFLD patients}

In NAFLD patients, there were a total of 1,090 deaths during the follow-up period (median of 18.8 years). Cardiovascularrelated mortality was the leading cause of death $(n=253)$, followed by malignancy $(n=256)$, lung disease $(n=76)$, diabetes $(n=66)$, cerebrovascular disease $(n=62)$, Alzheimer's disease $(n=22)$, and kidney disease $(n=15)$. Vitamin $\mathrm{D}$ deficiency was borderline significant for age-, race- and sexadjusted all-cause mortality (HR: $1.16,95 \% \mathrm{CI}$ : 0.99-1.36, $p=0.06)$. Vitamin $\mathrm{D}$ deficiency was prognostic in diabetesand Alzheimer's disease-related mortality (HR: 3.64, 95\%CI: 1.51-8.82 for diabetes, and HR: $4.80,95 \% \mathrm{CI}: 1.53-15.1$ for Alzheimer's disease). There was no statistically significant association between vitamin D deficiency and other leading causes of death. The vitamin D association with diabetes- and Alzheimer's disease-related mortality were not observed in non-NAFLD participants (Table S2).

\section{Discussion}

There is growing research interest in vitamin D's role in metabolic syndrome, along with the skeletal benefits of vitamin D. Since NAFLD is associated with metabolic syndrome and obesity, we investigated the association of vitamin $D$ and NAFLD severity as well as the prognostic value of vitamin $D$ in NAFLD. Our study suggests that vitamin D level is inversely 
Kim H.S. et al: Severity and mortality by vitamin D in NAFLD

\begin{tabular}{|c|c|c|c|}
\hline & $\begin{array}{l}\text { Vitamin D deficiency } \\
(n=4,991) 30.8 \% \\
{[95 \% \mathrm{CI}: 28.2-33.4]}\end{array}$ & $\begin{array}{l}\text { Without vitamin D } \\
\text { deficiency }(n=5,969) \\
69.2 \%[95 \% \mathrm{CI}: 66.6-71.8]\end{array}$ & $\begin{array}{l}\text { Adjusted } \\
p \text {-value* }\end{array}$ \\
\hline Age in years & $44.1 \pm 0.30$ & $42.7 \pm 0.16$ & $<0.001$ \\
\hline Sex as $\%$ male & $36.5 \pm 1.23$ & $52.3 \pm 0.54$ & $<0.001$ \\
\hline \multicolumn{4}{|l|}{ Race as $\%$} \\
\hline Non-Hispanic white & $55.2 \pm 1.97$ & $85.9 \pm 0.96$ & $<0.001$ \\
\hline Non-Hispanic black & $24.1 \pm 1.37$ & $4.1 \pm 0.35$ & \\
\hline Hispanic & $8.0 \pm 0.68$ & $4.0 \pm 0.39$ & \\
\hline Others & $12.7 \pm 1.28$ & $6.0 \pm 0.82$ & \\
\hline \multicolumn{4}{|l|}{ Education } \\
\hline Below college level & $61.1 \pm 1.51$ & $54.8 \pm 1.67$ & 0.92 \\
\hline$\geq$ College level & $38.9 \pm 1.51$ & $45.2 \pm 1.67$ & \\
\hline \multicolumn{4}{|l|}{ Poverty index ${ }^{\#}$} \\
\hline$\leq 1.3$ & $22.4 \pm 1.69$ & $14.4 \pm 0.91$ & 0.71 \\
\hline $1.3-1.85$ & $11.8 \pm 0.71$ & $9.64 \pm 0.93$ & \\
\hline$\geq 1.85$ & $65.7 \pm 1.84$ & $75.8 \pm 1.24$ & \\
\hline \multicolumn{4}{|l|}{ Smoking status as $\%$} \\
\hline Never & $47.3 \pm 1.28$ & $45.1 \pm 1.19$ & $<0.001$ \\
\hline Current & $29.6 \pm 1.07$ & $26.6 \pm 1.06$ & \\
\hline Former & $23.0 \pm 0.90$ & $28.3 \pm 0.83$ & \\
\hline Alcohol consumption as drinks/week & $3.95 \pm 0.17$ & $4.42 \pm 0.14$ & 0.271 \\
\hline \multicolumn{4}{|l|}{ Season of screening date } \\
\hline Spring & $27.7 \pm 0.42$ & $26.5 \pm 0.43$ & $<0.001$ \\
\hline Summer & $19.8 \pm 0.36$ & $33.9 \pm 0.50$ & \\
\hline Fall & $31.0 \pm 0.43$ & $28.8 \pm 0.47$ & \\
\hline Winter & $21.5 \pm 0.39$ & $10.8 \pm 0.24$ & \\
\hline \multicolumn{4}{|l|}{ Census region } \\
\hline Northeast & $16.5 \pm 1.62$ & $22.4 \pm 1.58$ & $<0.001$ \\
\hline Midwest & $18.3 \pm 1.58$ & $25.9 \pm 2.29$ & \\
\hline South & $40.0 \pm 3.36$ & $32.6 \pm 2.72$ & \\
\hline West & $25.2 \pm 3.70$ & $19.0 \pm 3.40$ & \\
\hline BMI in $\mathrm{kg} / \mathrm{m}^{2}$ & $28.3 \pm 0.20$ & $26.1 \pm 0.10$ & $<0.001$ \\
\hline Waist circumference in $\mathrm{cm}$ & $94.7 \pm 0.43$ & $91.1 \pm 0.26$ & $<0.001$ \\
\hline Waist to hip ratio & $0.91 \pm 0.002$ & $0.91 \pm 0.002$ & $<0.001$ \\
\hline Hypertension as \% & $25.8 \pm 1.03$ & $20.3 \pm 0.82$ & $<0.05$ \\
\hline Diabetes as $\%$ & $6.8 \pm 0.64$ & $4.2 \pm 0.35$ & $<0.05$ \\
\hline Insulin resistance as $\%$ & $25.4 \pm 1.33$ & $15.1 \pm 1.02$ & $<0.001$ \\
\hline HOMA-IR & $3.59 \pm 0.18$ & $2.64 \pm 0.93$ & $<0.01$ \\
\hline $\mathrm{HbA} 1 \mathrm{c}$ as $\%$ & $5.5 \pm 0.02$ & $5.3 \pm 0.02$ & $<0.001$ \\
\hline Hyperlipidemia as \% & $37.9 \pm 1.72$ & $34.7 \pm 1.23$ & 0.19 \\
\hline Total cholesterol in $\mathrm{mg} / \mathrm{dL}$ & $206.1 \pm 1.13$ & $203.5 \pm 0.92$ & 0.43 \\
\hline $\mathrm{LDL}$ in $\mathrm{mg} / \mathrm{dL}$ & $127.0 \pm 0.97$ & $125.7 \pm 0.97$ & 0.55 \\
\hline $\mathrm{HDL}$ in $\mathrm{mg} / \mathrm{dL}$ & $50.1 \pm 0.52$ & $49.7 \pm 0.41$ & 0.19 \\
\hline $\mathrm{TG}$ in $\mathrm{mg} / \mathrm{dL}$ & $147.3 \pm 2.89$ & $143.4 \pm 2.91$ & $<0.05$ \\
\hline AST in IU/L & $20.8 \pm 0.25$ & $20.8 \pm 0.19$ & 0.727 \\
\hline
\end{tabular}


Kim H.S. et al: Severity and mortality by vitamin D in NAFLD

Table 1. (continued)

\begin{tabular}{llll}
\hline & $\begin{array}{l}\text { Vitamin D deficiency } \\
(n=4,991) 30.8 \%\end{array}$ & $\begin{array}{l}\text { Without vitamin D } \\
\text { deficiency }(n=5,969) \\
69 \% \text { CI: 28.2-33.4] }\end{array}$ & $\begin{array}{l}\text { Adjusted } \\
p \text {-value* }\end{array}$ \\
\hline ALT in IU/L & $17.5 \pm 0.45$ & $17.5 \pm 0.44$ & 0.074 \\
r-GT in IU/L & $30.6 \pm 0.99$ & $26.6 \pm 0.69$ & $<0.05$ \\
Albumin in $\mathrm{g} / \mathrm{dL}$ & $4.1 \pm 0.02$ & $4.2 \pm 0.02$ & $<0.05$ \\
Platelet as $\times 10^{9} / \mathrm{L}$ & $282 \pm 2.9$ & $267 \pm 2.1$ & $<0.001$ \\
Leptin & $15.3 \pm 0.52$ & $10.4 \pm 0.30$ & $<0.001$ \\
IGF-1 & $256 \pm 4.18$ & $280 \pm 3.55$ & $<0.05$ \\
Vitamin D in $\mathrm{mg} / \mathrm{dL}$ & $15.1 \pm 0.10$ & $29.1 \pm 0.17$ & $<0.001$ \\
CRP & $0.45 \pm 0.01$ & $0.38 \pm 0.01$ & 0.06 \\
Metabolic syndrome as $\%$ & $37.3 \pm 1.72$ & $28.2 \pm 1.33$ & $<0.001$ \\
\hline
\end{tabular}

* adjusted by age, sex, and race.

\# Poverty index was classified with cut-offs of 1.3 and 1.85 according to the poverty guidelines.

related to the severity of NAFLD and liver fibrosis. Moreover, vitamin $D$ deficiency is significantly related to diabetes- and Alzheimer's disease-related mortality in NAFLD patients and has borderline significance in overall mortality.

Our findings can be supported by prior studies $7,8,28$ that reported a similar inverse relationship of vitamin $D$ and the degree of NAFLD. Nonetheless, the role of vitamin $D$ in the pathogenesis of NAFLD is still controversial. Since vitamin D is associated with known NAFLD risk factors, such as insulin resistance, diabetes and obesity, it is plausible that vitamin D may play a role in the development of NAFLD. ${ }^{1-4}$ Dasarathy et al. ${ }^{7}$ showed that 148 patients with biopsy-proven NAFLD had significantly lower vitamin D levels, when compared to controls, and that these lower concentrations were associated with significantly higher levels of steatosis and fibrosis in NAFLD patients. Additionally, Targher et al. ${ }^{9}$ also reported that in 60 consecutive patients with biopsy-proven NAFLD, vitamin D deficiency was closely associated with the histological severity of hepatic steatosis, necroinflammation and fibrosis, independent of HOMA-IR and metabolic syndrome.

Our findings also suggest that vitamin D's association with the degree of NAFLD and liver fibrosis is more prominent in female sex and the non-Hispanic white group (Tables 2 and 3). A possible explanation of vitamin D's prominent role in females could be from the fact that vitamin $D$ level has an inverse relationship to the level of progesterone and estradiol, which are thought to increase histologic severity in NAFLD patients. ${ }^{29,30}$ However, recently, Bril et al. ${ }^{31}$ reported no association of vitamin $D$ levels with insulin resistance or severity of $\mathrm{NASH}$, when matched for clinical parameters (BMI, total adiposity, and prevalence of pre-diabetes/type 2 diabetes).

Our findings also demonstrate that the statistically significant association disappeared after adjusting for known NAFLD risk factors in the full model (Tables 2 and 3). However, this

Table 2. Vitamin D level by degree of NAFLD on liver ultrasound findings

\begin{tabular}{|c|c|c|c|c|c|c|c|}
\hline & \multirow{2}{*}{$\begin{array}{l}\text { No NAFLD } \\
(n=6,945)\end{array}$} & \multicolumn{3}{|l|}{ NAFLD } & \multirow{2}{*}{$\begin{array}{l}\text { Unadjusted } \\
p \text {-value }\end{array}$} & \multirow[t]{2}{*}{$\begin{array}{l}\text { Limited } \\
\text { model } \\
p \text {-value* }\end{array}$} & \multirow{2}{*}{$\begin{array}{l}\text { Full model } \\
p \text {-value }\end{array}$} \\
\hline & & $\begin{array}{l}\text { Mild } \\
(n=1,491)\end{array}$ & $\begin{array}{l}\text { Moderate } \\
(n=1,707)\end{array}$ & $\begin{array}{l}\text { Severe } \\
(n=817)\end{array}$ & & & \\
\hline \multicolumn{8}{|l|}{ Total } \\
\hline $\begin{array}{l}\text { Vitamin } D \\
\text { in } \mathrm{mg} / \mathrm{dL}\end{array}$ & $25.1 \pm 0.29$ & $24.7 \pm 0.42$ & $23.7 \pm 0.37$ & $23.6 \pm 0.60$ & $<0.001$ & $<0.01$ & 0.189 \\
\hline \multicolumn{8}{|l|}{ Sex } \\
\hline Male & $26.6 \pm 0.33$ & $25.7 \pm 0.45$ & $25.0 \pm 0.50$ & $25.6 \pm 0.74$ & $<0.05$ & $<0.05$ & 0.216 \\
\hline Female & $23.9 \pm 0.34$ & $23.9 \pm 0.50$ & $22.3 \pm 0.49$ & $20.9 \pm 0.68$ & $<0.001$ & $<0.01$ & 0.514 \\
\hline \multicolumn{8}{|c|}{ Racial group } \\
\hline White & $26.9 \pm 0.31$ & $26.4 \pm 0.44$ & $25.1 \pm 0.44$ & $25.0 \pm 0.69$ & $<0.001$ & $<0.01$ & 0.256 \\
\hline Black & $16.9 \pm 0.39$ & $16.7 \pm 0.47$ & $16.4 \pm 0.49$ & $16.4 \pm 0.76$ & 0.296 & 0.112 & 0.144 \\
\hline Hispanic & $21.9 \pm 0.34$ & $21.1 \pm 0.47$ & $20.4 \pm 0.53$ & $20.5 \pm 0.48$ & $<0.001$ & $<0.001$ & 0.339 \\
\hline
\end{tabular}

*adjusted for age, sex, race, census region, season.

\# adjusted for age, sex, race, census region, season, hypertension, diabetes, dyslipidemia, BMI, metabolic syndrome, HOMA-IR, leptin, IGF-1. 

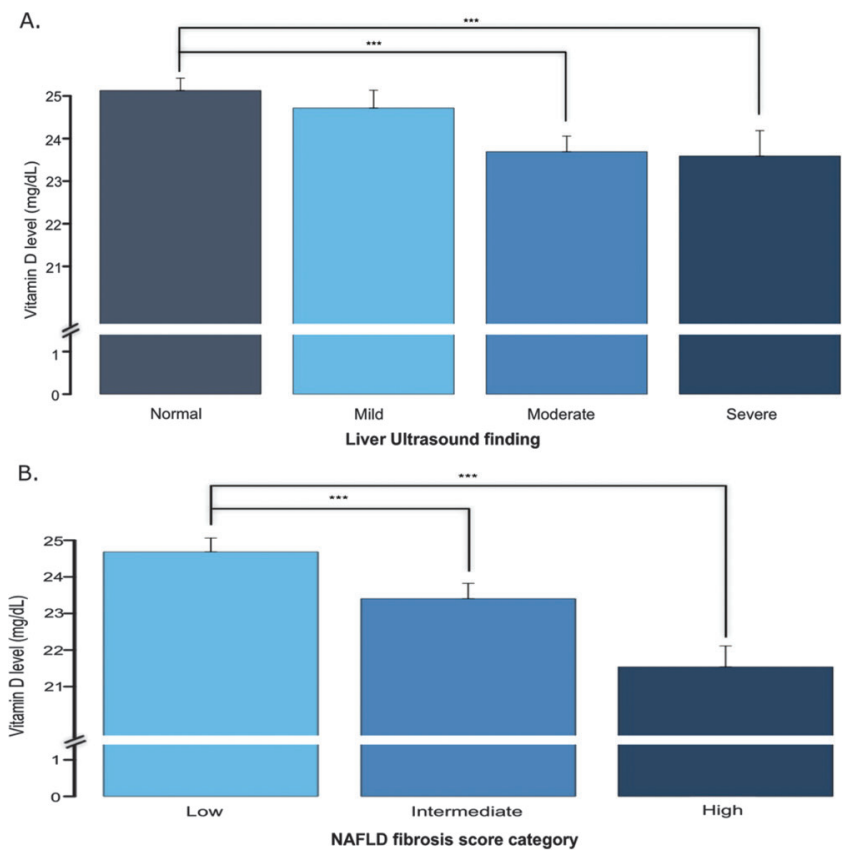

Fig. 2. Vitamin D level by the degree of NAFLD. (A) Vitamin $D$ level by the degree of NAFLD on liver ultrasound findings; (B) Vitamin D level by NFS category. $* * *$ Unadjusted $p$-value $<0.001$.

finding may not necessarily imply that vitamin $D$ does not play a role in NAFLD, but rather is confounded by other variables in the same causal pathway in the pathogenesis given vitamin D's role in the development of obesity, diabetes, insulin resistance and metabolic syndrome. ${ }^{1-4}$ Table S1 also showed high correlation between vitamin $\mathrm{D}$ and metabolic risk factors. Nelson et al. ${ }^{8}$ recently suggested a possible mechanism by which vitamin $D$ deficiency may be involved in proinflammatory pathways, such as MAPK and NF-kappa B in NASH pathogenesis. However, only a long-term follow-up study or clinical trials in NAFLD patients with vitamin D supplements will disclose the true effect of vitamin D in NAFLD pathogenesis. Thus, further investigation is warranted to
Kim H.S. et al: Severity and mortality by vitamin D in NAFLD

disclose a more concrete causal pathway between vitamin $D$ and other risk factors in the pathogenesis of NAFLD.

Our study also suggests that vitamin $D$ deficiency may be associated with mortality in NAFLD, especially related to diabetes and Alzheimer's disease. Several studies reported the mortality patterns of NAFLD, ${ }^{11,23,32,33}$ indicating cardiovascular complications as the most common cause of death followed by malignancy and liver disease, as compared to the general population. In our study, we focused on survival analyses only in NAFLD patients in terms of overall and top leading causes of death (cardiovascular, malignancy, cerebrovascular, lung, kidney, diabetes, and Alzheimer's disease). To our knowledge, this is the first study to report vitamin D's prognostic role in NAFLD. In the general population, a study suggested that low vitamin D level is associated with increased overall mortality and cardiovascular disease using NHANES III with follow-up mortality data through 2004. ${ }^{34}$

Our study, with a longer follow-up period (until 2011), also confirmed similar results in our whole participants (Table S3). Furthermore, the Ludwigshafen Risk and Cardiovascular Health study showed that in subjects with metabolic syndrome, vitamin $D$ deficiency is associated with higher allcause and cardiovascular disease-related mortality. ${ }^{35}$ Even though vitamin $D$ deficiency did not reach a statistically significant level in overall morality in NAFLD patients $(p=0.06$, Table 4), there was still a trend that was consistent with the findings in the general population and in people with metabolic syndrome. A reason for failing to reach significance could be due to the low power of this study.

Even though vitamin $D$ levels have been found to be inversely related to the risk of cardiovascular disease ${ }^{1}$, vitamin $D$ deficiency was not prognostic in cardiovascular disease-related mortality in NAFLD participants. Notably, the significant relationship to diabetes-related mortality was only observed in those participants with NAFLD (Table S2). Furthermore, it was interesting to find that vitamin $D$ has a prognostic role in Alzheimer's disease-related mortality in NAFLD. This association could be explained in part by the facts that vitamin $D$ deficiency is linked to cognitive decline $^{36}$ and falls ${ }^{37}$ among the elderly, and Alzheimer's disease can be induced by NAFLD, insulin resistance, and metabolic syndrome. ${ }^{38,39}$

Table 3. Vitamin D level by degree of NAFLD fibrosis score

\begin{tabular}{|c|c|c|c|c|c|c|}
\hline & $\begin{array}{l}\text { Low NFS } \\
(n=2,354)\end{array}$ & $\begin{array}{l}\text { Intermediate } \\
\text { NFS }(n=1,379)\end{array}$ & $\begin{array}{l}\text { High NFS } \\
(n=282)\end{array}$ & $\begin{array}{l}\text { Unadjusted } \\
p \text {-value }\end{array}$ & $\begin{array}{l}\text { Limited } \\
\text { model }^{*} \\
\text { ( } p \text {-value) }\end{array}$ & $\begin{array}{l}\text { Full model }^{*} \\
\text { ( } p \text {-value })\end{array}$ \\
\hline \multicolumn{7}{|l|}{ Total } \\
\hline $\begin{array}{l}\text { Vitamin } D \text { in } \\
\mathrm{mg} / \mathrm{dL}\end{array}$ & $24.7 \pm 0.38$ & $23.4 \pm 0.42$ & $21.5 \pm 0.57$ & $<0.001$ & $<0.05$ & 0.595 \\
\hline \multicolumn{7}{|l|}{ Sex } \\
\hline Male & $25.7 \pm 0.42$ & $25.1 \pm 0.45$ & $24.4 \pm 0.79$ & 0.155 & 0.247 & 0.520 \\
\hline Female & $23.7 \pm 0.49$ & $21.5 \pm 0.54$ & $19.2 \pm 0.75$ & $<0.001$ & $<0.05$ & 0.391 \\
\hline \multicolumn{7}{|l|}{ Racial group } \\
\hline White & $26.6 \pm 0.41$ & $24.6 \pm 0.46$ & $22.9 \pm 0.73$ & $<0.001$ & $<0.05$ & 0.369 \\
\hline Black & $16.2 \pm 0.40$ & $16.6 \pm 0.60$ & $16.9 \pm 0.97$ & 0.236 & 0.329 & 0.908 \\
\hline Hispanic & $21.1 \pm 0.46$ & $20.2 \pm 0.47$ & $17.1 \pm 1.04$ & $<0.05$ & 0.261 & 0.369 \\
\hline
\end{tabular}

* adjusted for age, sex, race, census region, season.

\# adjusted for age, sex, race, census region, season, hypertension, diabetes, dyslipidemia, BMI, metabolic syndrome, HOMA-IR, leptin, IGF-1. 
Kim H.S. et al: Severity and mortality by vitamin D in NAFLD

Table 4. Mortality by vitamin D level in NAFLD patients

\begin{tabular}{|c|c|c|c|}
\hline \multirow[b]{2}{*}{ Variable } & \multirow{2}{*}{$\begin{array}{l}\text { No. of } \\
\text { deaths }\end{array}$} & \multicolumn{2}{|c|}{ Age, sex, race adjusted model } \\
\hline & & $\mathrm{HR}(95 \% \mathrm{CI})$ & $p$-value \\
\hline \multicolumn{4}{|l|}{ All-cause mortality } \\
\hline Vitamin $D \geq 20$ mg/dL & 573 & REF & 0.06 \\
\hline Vitamin $\mathrm{D}<20 \mathrm{mg} / \mathrm{dL}$ & 517 & $1.16(0.99-1.36)$ & \\
\hline \multicolumn{4}{|l|}{ Cardiovascular disease } \\
\hline Vitamin $D \geq 20 \mathrm{mg} / \mathrm{dL}$ & 131 & REF & 0.29 \\
\hline Vitamin $\mathrm{D}<20 \mathrm{mg} / \mathrm{dL}$ & 122 & $1.28(0.81-2.03)$ & \\
\hline \multicolumn{4}{|l|}{ Malignancy } \\
\hline Vitamin $\mathrm{D} \geq 20 \mathrm{mg} / \mathrm{dL}$ & 131 & REF & 0.89 \\
\hline Vitamin $\mathrm{D}<20 \mathrm{mg} / \mathrm{dL}$ & 125 & $1.03(0.70-1.50)$ & \\
\hline \multicolumn{4}{|l|}{ Cerebrovascular disease } \\
\hline Vitamin $\mathrm{D} \geq 20 \mathrm{mg} / \mathrm{dL}$ & 34 & REF & 0.64 \\
\hline Vitamin $\mathrm{D}<20 \mathrm{mg} / \mathrm{dL}$ & 28 & $1.26(0.48-3.34)$ & \\
\hline \multicolumn{4}{|l|}{ Lung disease } \\
\hline Vitamin D $\geq 20 \mathrm{mg} / \mathrm{dL}$ & 46 & REF & 0.33 \\
\hline Vitamin $\mathrm{D}<20 \mathrm{mg} / \mathrm{dL}$ & 30 & $1.52(0.66-3.52)$ & \\
\hline \multicolumn{4}{|l|}{ Kidney disease } \\
\hline Vitamin D $\geq 20$ mg/dL & 6 & REF & 0.91 \\
\hline Vitamin $\mathrm{D}<20 \mathrm{mg} / \mathrm{dL}$ & 9 & $1.11(0.19-6.37)$ & \\
\hline \multicolumn{4}{|l|}{ Diabetes } \\
\hline Vitamin $D \geq 20 \mathrm{mg} / \mathrm{dL}$ & 36 & REF & $<0.01$ \\
\hline Vitamin $\mathrm{D}<20 \mathrm{mg} / \mathrm{dL}$ & 30 & $3.64(1.51-8.82)$ & \\
\hline \multicolumn{4}{|l|}{ Alzheimer's disease } \\
\hline Vitamin $D \geq 20 \mathrm{mg} / \mathrm{dL}$ & 11 & REF & $<0.01$ \\
\hline Vitamin $\mathrm{D}<20 \mathrm{mg} / \mathrm{dL}$ & 11 & $4.80(1.53-15.1)$ & \\
\hline
\end{tabular}

The strength of this study was that our findings were based on nationally representative data that was linked with mortality information with median follow-up of over 18 years. This allowed us to investigate the long-term effects of vitamin D deficiency and assess the mortality outcomes in NAFLD. Limitations of this study included that the NAFLD was not confirmed by liver biopsy. However, previous studies reported good accuracy of screening by liver ultrasound, ${ }^{23,40}$ and a non-invasive diagnostic tool may be more appropriate in a large epidemiological study. Due to data restrictions on less common causes of death, liver-related mortality information could not be obtained in the public version of NHANES mortality data. However, since liver-related deaths were even less common than that of kidney-related deaths, we may assume that the liver-related mortality analysis would likely be underpowered. Additionally, participants with other liver diseases, such as autoimmune hepatitis or primary biliary cholangitis, could not be excluded. Lastly, given the cross-sectional study design, a causal relationship of vitamin D in NAFLD could not be disclosed.

In conclusion, vitamin $\mathrm{D}$ level was inversely related to the degree of liver steatosis and fibrosis. Moreover, vitamin D deficiency was associated with an increased risk of diabetesand Alzheimer's disease-related mortality in NAFLD patients.
Further prospective cohort or randomized trials are warranted to confirm our findings and to gain in-depth insight on vitamin D's role with other metabolic risk factors in NAFLD pathogenesis.

\section{Acknowledgments}

This work was supported in part by the National Research Foundation of Korea (Grant No. 2014R1A2A10052872 to Sung-Hoon Kim).

\section{Conflict of interest}

The authors have no conflict of interests related to this publication.

\section{Author contributions}

Study and design, statistical analysis, administrative, technical, or material support, and study supervision (HSK, SHK, $\mathrm{NP}$ ), acquisition, analysis or interpretation of data, drafting of the manuscript, and critical revision of the manuscript for important intellectual content (HSK, LR, NK, SHK, NP), full 
access to all the data in the study and takes responsibility for the integrity of the data and the accuracy of the data analysis (HSK). All authors approved the final version of the manuscript.

\section{Disclaimer}

This work was presented in part as an oral presentation at the American College of Gastroenterology 2016 conference (Las Vegas, NV, USA).

\section{References}

[1] Wang $\mathrm{TJ}$, Pencina $\mathrm{MJ}$, Booth $\mathrm{SL}$, Jacques $\mathrm{PF}$, Ingelsson $\mathrm{E}$, Lanier $\mathrm{K}$, et al. Vitamin D deficiency and risk of cardiovascular disease. Circulation 2008; 117:503-511. doi: 10.1161/CIRCULATIONAHA.107.706127.

[2] Palomer X, González-Clemente JM, Blanco-Vaca F, Mauricio D. Role of vitamin $\mathrm{D}$ in the pathogenesis of type 2 diabetes mellitus. Diabetes Obes Metab 2008;10:185-197. doi: 10.1111/j.1463-1326.2007.00710.x

[3] Maki KC, Fulgoni VL 3rd, Keast DR, Rains TM, Park KM, Rubin MR. Vitamin D intake and status are associated with lower prevalence of metabolic syndrome in U.S. adults: National Health and Nutrition Examination Surveys 2003-2006. Metab Syndr Relat Disord 2012;10:363-372. doi: 10.1089/ met.2012.0020.

[4] Tarantino G, Finelli C. What about non-alcoholic fatty liver disease as a new criterion to define metabolic syndrome? World J Gastroenterol 2013;19: 3375-3384. doi: 10.3748/wjg.v19.i22.3375.

[5] Fattahi MR, Niknam R, Safarpour A, Sepehrimanesh M, Lotfi M. The prevalence of metabolic syndrome in non-alcoholic fatty liver disease; a population-based study. Middle East J Dig Dis 2016;8:131-137. doi: 10.15171/ mejdd.2016.18.

[6] Rinella ME. Nonalcoholic fatty liver disease: a systematic review. JAMA 2015; 313:2263-2273. doi: 10.1001/jama.2015.5370.

[7] Dasarathy J, Periyalwar P, Allampati S, Bhinder V, Hawkins C, Brandt P, et al. Hypovitaminosis $D$ is associated with increased whole body fat mass and greater severity of non-alcoholic fatty liver disease. Liver Int 2014;34: e118-e127. doi: 10.1111/liv.12312.

[8] Nelson JE, Roth CL, Wilson LA, Yates KP, Aouizerat B, Morgan-Stevenson $\mathrm{V}$ et al. Vitamin $D$ deficiency is associated with increased risk of non-alcoholic steatohepatitis in adults with non-alcoholic fatty liver disease: possible role for MAPK and NF-кB? Am J Gastroenterol 2016;111:852-863. doi: 10. 1038/ajg.2016.51.

[9] Targher G, Bertolini L, Scala L, Cigolini M, Zenari L, Falezza G, et al. Associations between serum 25-hydroxyvitamin D3 concentrations and liver histology in patients with non-alcoholic fatty liver disease. Nutr Metab Cardiovasc Dis 2007;17:517-524. doi: 10.1016/j.numecd.2006.04.002.

[10] Adams LA, Lymp JF, St Sauver J, Sanderson SO, Lindor KD, Feldstein A, et al. The natural history of nonalcoholic fatty liver disease: a population-based cohort study. Gastroenterology 2005;129:113-121. doi: 10.1053/j.gastro. 2005.04.014.

[11] Ong JP, Pitts A, Younossi ZM. Increased overall mortality and liver-related mortality in non-alcoholic fatty liver disease. J Hepatol 2008;49:608-612. doi: 10.1016/j.jhep.2008.06.018.

[12] Targher G, Day CP, Bonora E. Risk of cardiovascular disease in patients with nonalcoholic fatty liver disease. N Engl J Med 2010;363:1341-1350. doi: 10. 1056/NEJMra0912063.

[13] National Center for Health Statistics. Plan and operation of the Third National Health and Nutrition Examination Survey, 1988-94. Available from: https: //www.cdc.gov/nchs/data/series/sr_01/sr01_032.pdf, accessed July 1994.

[14] National Health and Nutrition Examination Survey III; Body Measurements (Anthropometry). Available from: https://www.cdc.gov/nchs/data/nhanes/ nhanes3/cdrom/nchs/manuals/anthro.pdf, accessed October 1988.

[15] National Center for Health Statistics. National Health and Nutrition Examination Survey III Cycle 2: pulse and blood pressure procedures for household inteviewers. Available from: https://wwwn.cdc.gov/nchs/data/nhanes3/ manuals/pressure.pdf, accessed July 1993.

[16] Gunter EW, Lewis BG, Koncikowski SM. Laboratory procedures used for the Third National Health and Nutrition Examination Survey (NHANES III), 1988-1994. Available from: https://www.cdc.gov/nchs/data/nhanes/ nhanes3/cdrom/nchs/manuals/labman.pdf, accessed 1996.

[17] Liangpunsakul S, Chalasani N. Serum vitamin D concentrations and unexplained elevation in ALT among US adults. Dig Dis Sci 2011;56:2124-2129. doi: 10.1007/s10620-011-1707-x.

[18] National Health and Nutrition Examination Survey. 2013-2014 data documentation, codebook, and frequencies. Available from: https://wwwn.cdc. gov/Nchs/Nhanes/2013-2014/INQ_H.htm, accessed October 2015.
[19] Expert Panel on Detection, Evaluation, and Treatment of High Blood Cholesterol in Adults. Executive summary of the third report of the National Cholesterol Education Program (NCEP) expert panel on detection, evaluation, and treatment of high blood cholesterol in adults (adult treatment panel III). JAMA 2001;285:2486-2497. doi: 10.1001/jama.285.19.2486.

[20] National Health and Nutrition Examination Survey. Analytical Note for 25Hydroxyvitamin D. Data Analysis using NHANES III (1988-1994), NHANES 2001-2006, and NHANES 2007-2010 (October 2015). Available from: https://wwwn.cdc.gov/Nchs/Nhanes/VitaminD/AnalyticalNote.aspx.

[21] Ma Z, Gingerich RL, Santiago JV, Klein S, Smith CH, Landt M. Radioimmunoassay of leptin in human plasma. Clin Chem 1996;42:942-946.

[22] Diener A, Rohrmann S. Associations of serum carotenoid concentrations and fruit or vegetable consumption with serum insulin-like growth factor (IGF)-1 and IGF binding protein-3 concentrations in the Third National Health and Nutrition Examination Survey (NHANES III). J Nutr Sci 2016;5: e13. doi: $10.1017 /$ jns.2016.1.

[23] Kim D, Kim WR, Kim HJ, Therneau TM. Association between noninvasive fibrosis markers and mortality among adults with nonalcoholic fatty liver disease in the United States. Hepatology 2013;57:1357-1365. doi: 10. 1002/hep.26156.

[24] Angulo P, Hui JM, Marchesini G, Bugianesi E, George J, Farrell GC, et al. The NAFLD fibrosis score: a noninvasive system that identifies liver fibrosis in patients with NAFLD. Hepatology 2007;45:846-854. doi: 10.1002/hep. 21496.

[25] National Centers for Health Statistics. NCHS. Surveys: 2011 Linked Mortality Files. Available from: https://www.cdc.gov/nchs/data/datalinkage/public_ use_data_dictionary_11_17_2015.pdf, accessed November 17, 2015.

[26] Lumley T. Analysis of complex survey samples. Journal of Statistical Software 2004;9:1-19. doi: 10.18637/jss.v009.i08.

[27] Breslow NE, Day NE. Statistical methods in cancer research. Volume II-The design and analysis of cohort studies. IARC Sci Publ 1987;(82):1-406.

[28] Barchetta I, Angelico F, Del Ben M, Baroni MG, Pozzilli P, Morini S, et al. Strong association between non alcoholic fatty liver disease (NAFLD) and low $25(\mathrm{OH})$ vitamin $D$ levels in an adult population with normal serum liver enzymes. BMC Med 2011;9:85. doi: 10.1186/1741-7015-9-85.

[29] Yang JD, Abdelmalek MF, Guy CD, Gill RM, Lavine JE, Yates K, et al. Patient sex, reproductive status, and synthetic hormone use associate with histologic severity of nonalcoholic steatohepatitis. Clin Gastroenterol Hepatol 2017;15:127-131.e2. doi: 10.1016/j.cgh.2016.07.034.

[30] Knight JA, Wong J, Blackmore KM, Raboud JM, Vieth R. Vitamin D association with estradiol and progesterone in young women. Cancer Causes Control 2010;21:479-483. doi: 10.1007/s10552-009-9466-0.

[31] Bril F, Maximos M, Portillo-Sanchez P, Biernacki D, Lomonaco R, Subbarayan S, et al. Relationship of vitamin D with insulin resistance and disease severity in non-alcoholic steatohepatitis. J Hepatol 2015;62:405-411. doi: 10.1016/j. jhep.2014.08.040.

[32] Lazo M, Hernaez R, Bonekamp S, Kamel IR, Brancati FL, Guallar E, et al. Non-alcoholic fatty liver disease and mortality among US adults: prospective cohort study. BMJ 2011;343:d6891. doi: 10.1136/bmj.d6891.

[33] Treeprasertsuk S, Björnsson E, Enders F, Suwanwalaikorn S, Lindor KD. NAFLD fibrosis score: a prognostic predictor for mortality and liver complications among NAFLD patients. World J Gastroenterol 2013;19:1219-1229. doi: $10.3748 /$ wjg.v19.i8.1219.

[34] Melamed ML, Michos ED, Post W, Astor B. 25-hydroxyvitamin D levels and the risk of mortality in the general population. Arch Intern Med 2008;168: 1629-1637. doi: 10.1001/archinte.168.15.1629.

[35] Thomas GN, ó Hartaigh B, Bosch JA, Pilz S, Loerbroks A, Kleber ME, et al. Vitamin $D$ levels predict all-cause and cardiovascular disease mortality in subjects with the metabolic syndrome: the Ludwigshafen Risk and Cardiovascular Health (LURIC) Study. Diabetes Care 2012;35:1158-1164. doi: 10. 2337/dc11-1714.

[36] Llewellyn DJ, Lang IA, Langa KM, Muniz-Terrera G, Phillips CL, Cherubini A, et al. Vitamin $D$ and risk of cognitive decline in elderly persons. Arch Intern Med 2010;170:1135-1141. doi: 10.1001/archinternmed.2010.173.

[37] Bischoff-Ferrari HA, Dawson-Hughes B, Willett WC, Staehelin HB, Bazemore MG, Zee RY, et al. Effect of Vitamin D on falls: a meta-analysis. JAMA 2004; 291:1999-2006. doi: 10.1001/jama.291.16.1999.

[38] Ghareeb DA, Hafez HS, Hussien HM, Kabapy NF. Non-alcoholic fatty liver induces insulin resistance and metabolic disorders with development of brain damage and dysfunction. Metab Brain Dis 2011;26:253-267. doi: 10.1007/s11011-011-9261-y.

[39] Kim DG, Krenz A, Toussaint LE, Maurer KJ, Robinson SA, Yan A, et al. Non-alcoholic fatty liver disease induces signs of Alzheimer's disease (AD) in wild-type mice and accelerates pathological signs of $A D$ in an $A D$ model. J Neuroinflammation 2016;13:1. doi: 10.1186/s12974-015-0467-5.

[40] Hernaez R, Lazo M, Bonekamp S, Kamel I, Brancati FL, Guallar E, et al. Diagnostic accuracy and reliability of ultrasonography for the detection of fatty liver: a meta-analysis. Hepatology 2011;54:1082-1090. doi: 10 . 1002/hep.24452. 